\title{
Effect of Variation Aluminum Oxide Concentration on the Modified Novolac Stalk Composite
}

\author{
Magda G. El-Meligy, Zenat A. Nagieb, and K. B. Isis \\ Cellulose and Paper Department, National Research Center, Dokki, 12622 Giza, Egypt \\ Correspondence should be addressed to Magda G. El-Meligy, gemeligy@yahoo.com
}

Received 9 February 2012; Accepted 20 March 2012

Academic Editors: C. Chen, A. Gervasini, and R. Mariscal

Copyright (๑) 2012 Magda G. El-Meligy et al. This is an open access article distributed under the Creative Commons Attribution License, which permits unrestricted use, distribution, and reproduction in any medium, provided the original work is properly cited.

Strength properties and water repellency of cotton stalk fibers esterified with propionic anhydride that are used as reinforcing of novolac resin were greatly improved than untreated. Adding aluminum oxide to the prepared composite improved bending strength and enhanced water repellant. The alternating current conductivity and dielectric constant were greatly enhanced at different frequencies by adding aluminum oxide. The more percent of aluminum oxide, the more value of alternating current conductivity and lower value of dielectric constant were obtained at different frequencies. Infrared and X-ray diffraction as well as scanning electron microscope were studied.

\section{Introduction}

The development of polymer composites from renewable raw materials has been increased considerably during the last few years [1-7]. Natural fiber-based lignocellulosic materials are now considered as potential substitutes for toxic synthetic fibers for the preparation of reinforced composites. The advantages of natural fibers include easy availability, renewability, biodegradability, nontoxicity, low cost, low specific gravity, high toughness, acceptable specific strength, and enhanced energy recovery, and so forth, $[8,9]$. Synthetic fibers can cause health problems and are on the whole difficult to utilize, since composites with high synthetic fiber content have low energy values and high ash content [3]. It has been observed that effective utilization of lignocellulosic fibers as reinforcement in polymer composites provides positive environmental benefits with respect to ultimate disposability and the most excellent utilization of raw materials [10, 11]. Currently, a variety of studies are conducted to find ways to use lignocellulosic natural fibers instead of synthetic fibers in various applications $[8,9,12]$. Compression molding is one of the most suitable techniques to process lignocellulosic fibre-based polymeric material $[6,7]$. The properties of biofibers mainly depend on the source, age, and separating techniques of the fiber. These properties generally vary from plant to plant according to climatic conditions and other factors. These fibers consist of cellulose, hemicelluloses, lignin, and extraneous components. Cellulose is principally responsible for the strength of natural fiber because of its specific properties such as high degree of polymerization and linear orientation. Lignocelluloses fiber-based polymer composite materials have made a primary contribution to the well-being and technological development of mankind [1$3,13,14]$. The most important factors in the development of natural fiber reinforced composites are fiber dispersion and fiber matrix interaction $[3,6-8,15]$. The commercial importance of polymers has derived intense applications in the form of composites in various fields, namely, in aerospace, automotive, marine, infrastructure, the military, and so forth. Among various polymer matrixes phenol-formaldehyde (PF) resin is a widely used thermosetting adhesive for exterior-grade natural fiber reinforced composites. It is one of the dominant resins used in oriented strand board (OSB) and plywood production.

Corresponding phenolic resins are widely used because of their low cost, dimensional stability, age resistance, and high tensile strength. These resins have been used commercially in many applications such as molding compounds, laminates, adhesives, and shell molds for metals and electrical insulation. Although conventional phenolics are already 
considered as temperature resistant polymers and are currently in use in many applications, some of the properties of phenolics are in need of further improvement to meet the ever-increasing performance requirements when combined with low temperature resistant materials such as natural lignocellulosics $[8,16]$. Inorganic component is dispersed within an organic matrix and may be include simple to reinforce a tough. It is used to impart more sophisticated properties to the materials (e.g., magnetic or electrical properties). Metal oxide is used to decorate objects, for corrosion inhibition, to improve solider ability, to harden, to improve wear ability, to alter conductivity, and also for radiation shielding $[17,18]$. The aim of our work is to study effect of adding different concentrations of aluminum oxide on modified novolac composites on mechanical, morphology, water repellency, and electric properties.

\section{Experimental: Materials and Methods}

Materials. Cotton stalk, propionic anhydride, novolac and aluminium oxide.

2.1. Treatment of Cotton Stalk. Cotton stalk was grinding into 30 mesh then extracted by methanol benzene $(1: 1)$ for $6 \mathrm{hr}$ to get rid of resins. It was esterified propionic anhydride according to the method described in [19].

2.2. Preparation of Composite. The composite samples were prepared from the ground cotton stalk by impregnation in polymer solution (certain weight of novolac in acetone). $50 \mathrm{~g}$ of ground cotton stalk were impregnated in the polymer solution and stirred properly, then left for $24 \mathrm{hrs}$ at room temperature. The solvent was evaporated and dried.

The homogeneous mixture was then processed as follows: $50 \mathrm{~g}$ dry sample were placed in a disc form, diameter $15 \mathrm{~cm}$, heated to $150^{\circ} \mathrm{C}$, and then pressed under $150 \mathrm{~kg} / \mathrm{cm}^{2}$ disc for $5 \mathrm{~min}$.

2.3. Measurements. The composite samples were subjected to the following measurements.

2.3.1. Water Absorption. A specific weight and thickness of such composites were immersed in boiling water for $2 \mathrm{~h}$ and in water for $24 \mathrm{~h}$ and 7 days at room temperature. After that, thickness and weights of the composites were measured again.Water absorption percent can be calculated as follows:

$$
\text { Water absorption } \%=\frac{W_{w}-W_{i}}{W_{i}} \times 100 \text {, }
$$

where $W_{i}$ and $W_{w}$ are the initial and wet weights of the composites, respectively.

This test was measured according to the method of D 57081 ASTM [20].
2.3.2. Bending Strength. Bending strength is defined as the maximum load that should be applied to the sample to be broken and can be calculated by the following relation:

$$
\text { Bending strength }=\frac{3 p L}{2 b d^{2}}\left(\mathrm{~N} / \mathrm{mm}^{2}\right),
$$

where $p$ is the maximum bending load, $L$ is the length of span, $b$ is the width of specimen, and $d$ is the thickness of specimen. LLoyD Instrument LTD was used to measure bending strength.

2.3.3. Infrared Spectra. The infrared spectra for treated and untreated cotton stalk is measured by using apparatus Jocco FTIR spectrophotometer, Japan. The samples were measured as $\mathrm{KBr}$ discs.

2.3.4. Scanning Electron Microscopy. Scanning electron microscopy (SEM) of fractured surfaces of composite test specimens were conducted on JEDL JEM-100 S electron microscope using the gold.

2.3.5. X-Ray Diffraction Method. The crystallinity of samples was measured by X-ray diffraction (Bruker $\mathrm{D}_{8}$ ADVANCE, a $\mathrm{Cu} \mathrm{K} \alpha$ target with a nickel filter was used). The powder samples were pressed into discs in a special holder. The samples were scanned for a range of 20 from 10 to 30 .

2.3.6. Electrical Measurements. The dielectric constant $\left(\varepsilon^{\prime}\right)$ and the conductivity $(\sigma)$ of the samples were calculated using the following equations, respectively:

$$
\varepsilon^{\prime}=\left(\frac{C}{E o}\right) \times\left(\frac{d}{A}\right), \quad \sigma A=G \times\left(\frac{d}{A}\right),
$$

where $C$ is the capacitance of the sample in Farad, $\varepsilon_{o}$ is the capacitivity of vaccum $(8.85 E-12 \mathrm{~F} / \mathrm{m}), d$ is the sample thickness, $A$ is the area of the used electrode, $G$ is the conductance, $d$ and $A$ were measured in $\mathrm{m}$ for dielectric constant but for conductivity, they were measured in $\mathrm{cm}$. Capacitance $(C)$ and conductance were measured using computerized HIOKI 3532-50 LCR HITESTER, Japan. All the samples were measured at room temperature $\left(25^{\circ} \mathrm{C}\right)$ and at different frequencies ranging from 500 to $20.000 \mathrm{~Hz}$.

\section{Results and Discussion}

3.1. Strength Properties and Water Absorption. The impact of adding of different concentration of aluminum oxide on composites, the mechanical properties were investigated.

Table 1 shows that the composite prepared from treated cotton stalk by propionic anhydride have higher bending strength and lower water absorption compared to the untreated. This is due to formation of hydrogen bonding that improved the fiber-matrix reaction. Consequently, developing of highly cross linked interface region between the fiber and matrix increased the strength of the interfacial bonding between them [21].

It was clear from Table 1 and Figure 1 that the more percentage of aluminum oxide added, the more MOR which 
TABLE 1: Bending strength and water absorption of the composites prepared from untreated and treated cotton stalk containing novolac and different concentrations of $\mathrm{Al}_{2} \mathrm{O}_{3}$. (Conce. polymer $30 \%$, temp. $160^{\circ} \mathrm{C}$, pressure $150 \mathrm{~kg} / \mathrm{cm}^{2}$, time of press $5 \mathrm{~min}$.).

\begin{tabular}{|c|c|c|c|c|}
\hline \multirow{2}{*}{ Type of composite } & \multirow[b]{2}{*}{$\begin{array}{l}\text { Bending strength } \\
\mathrm{N} / \mathrm{mm}^{2} \text { (MOR) }\end{array}$} & \multicolumn{3}{|c|}{ Water absorption } \\
\hline & & $\begin{array}{l}\text { After immersion in } \\
\text { boiling water for } 2 \mathrm{hr}\end{array}$ & $\begin{array}{l}\text { After immersion in } \\
\text { water for } 24 \mathrm{hr}\end{array}$ & $\begin{array}{l}\text { After immersion in } \\
\text { water for } 7 \text { days }\end{array}$ \\
\hline $\begin{array}{l}\text { Untreated composite containing } 30 \% \\
\text { novolac resin }\end{array}$ & 11.5 & 27.3 & 26.8 & 39.1 \\
\hline $\begin{array}{l}\text { Treated composite containing 30\% } \\
\text { novolac resin }\end{array}$ & 15.7 & 21.6 & 21.6 & 32.1 \\
\hline $\begin{array}{l}\text { Treated composite containing } 30 \% \\
\text { novolac resin and } 2 \% \text { aluminum oxide }\end{array}$ & 18.6 & 20.1 & 19.7 & 30.8 \\
\hline $\begin{array}{l}\text { Treated composite containing } 30 \% \\
\text { novolac resin and } 4 \% \text { aluminum oxide }\end{array}$ & 23.5 & 19.5 & 19.0 & 27.8 \\
\hline $\begin{array}{l}\text { Treated composite containing } 30 \% \\
\text { novolac resin and } 6 \% \text { aluminum oxide }\end{array}$ & 29.7 & 15.1 & 15.1 & 22.4 \\
\hline
\end{tabular}

Treated composite: the composite treated by propionic anhydride.

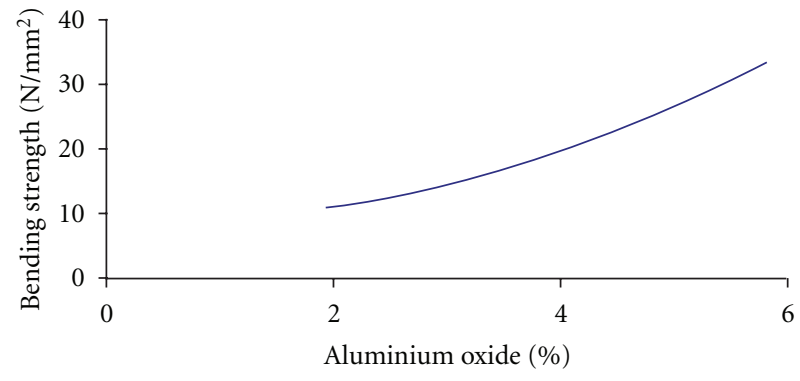

FIGURE 1: Effect of aluminum oxide \% on the bending strength of the treated composite.

reached $29.7 \mathrm{~N} / \mathrm{mm}$ is obtained. Since the addition of aluminum oxide giving well-dispersed nanoscale domains that have good interfacial adhesion to the matrix. This lead to improve solider ability and to harden [16]. Generally the mechanical properties enhanced with increasing the percentage of aluminum oxide, due to higher modulus of composite. Aluminum oxide can reinforce the matrix and increase the modulus. Also we observed that increasing the addition of percentage of aluminum oxide leads to decrease in water absorption originates from decreasing void content of the composite as shown in Table 1 and Figure 2. The more percentage of aluminum oxide the more enhancing water repelling reached 15.1 for both 2 and 24 hours and $22.4 \%$ for 7 days. This is due to responsible for reacting with free$\mathrm{OH}$ groups in cellulosic structure. It behaves as compatibles and become more hydrophobic, that is, reduces the water absorption [19].

3.2. Infrared Spectroscopy. It is clear from Figures 3(a)-3(c) that broad absorption bands appear at 3422, 3985, and $3409 \mathrm{~cm}^{-1}$, respectively, which are attributed to the stretching vibration of hydroxyl groups. The peaks at 1634, 1214, and $1100 \mathrm{~cm}^{-1}$ correspond to the vibration of carboxylic acid groups. In the IR spectra Figures 3(a)-3(c), the bands around $1640,1520,1380,1290,180$, and $1020 \mathrm{~cm}^{-1}$ could

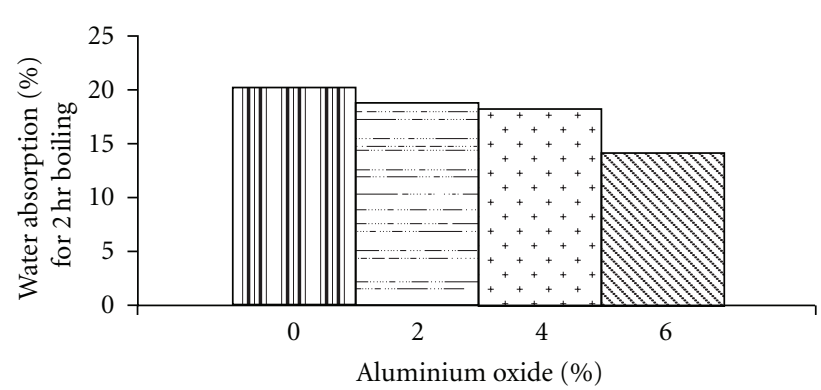

(a)

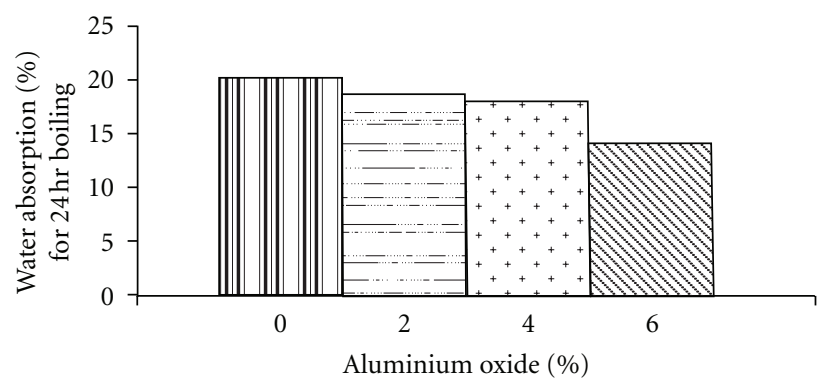

(b)

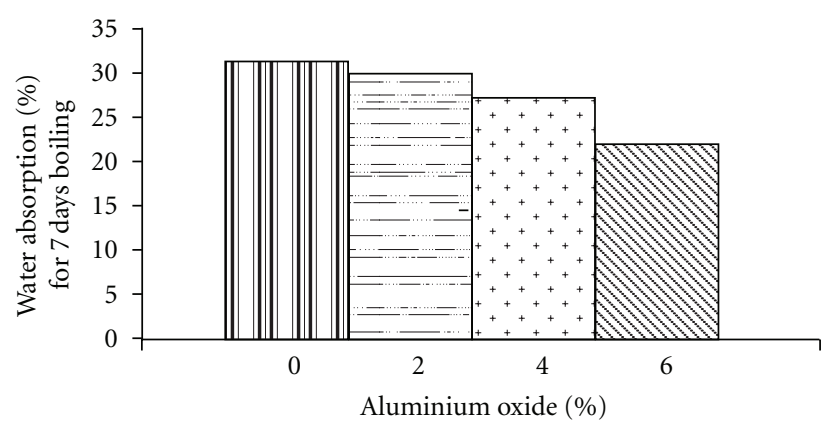

(c)

FIGURE 2: Effect of aluminum oxide \% on the water absorption of the treated composite. (a) After immersion in boiling water for $2 \mathrm{hr}$. (b) After immersion in water for $24 \mathrm{hr}$. (c) After immersion in water for 7 days. 


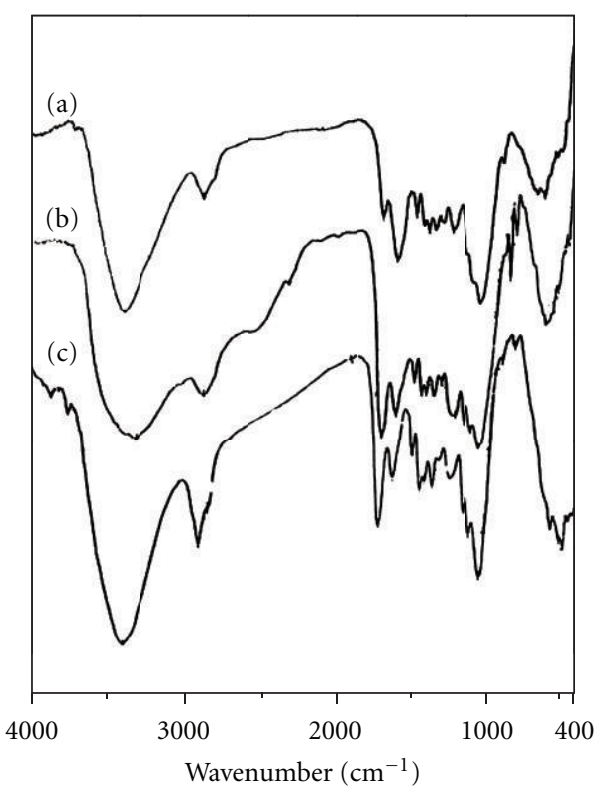

FIgURE 3: Infra red spectra. (a) Untreated composite containing $30 \%$ novolac resin. (b) Treated composite containing 30\% novolac resin. (c) Treated composite containing 30\% novolac resin and aluminum oxide.

be assigned to the $\mathrm{C}=\mathrm{O}$ stretching, $\mathrm{CH}_{2}$ bending, the asymmetric stretching of $\mathrm{CH}_{2}$ the $\mathrm{C}-\mathrm{O}$ stretching of $\mathrm{CH}_{2}-\mathrm{O}-$ $\mathrm{CH}_{2}-$, and the $\mathrm{C}-\mathrm{O}$ stretching in $\mathrm{CH}_{2}-\mathrm{OH}$, respectively, [22]. Moreover, no absorption bands was observed for the $\mathrm{C}=\mathrm{O}$ ester group in Figure 3(a). Meanwhile, strong stretching vibration bands for $\mathrm{C}=\mathrm{O}$ ester appeared at $1735,1726 \mathrm{~cm}^{-1}$ in Figures 3(b) and 3(c) which confirm the esterification process [23].

3.3. Scanning Electronic Microscopy. Figures 4(a) and 4(b) present the fractures of phenolic composite with cotton stalk. The micrograph of novolac composite indicates that different lamella is separated from each other by amphorous region and voids present in very small number. But in case of (b) treated cotton stalk composite by propionic anhydride to become less a void and less fractures.

In Figures 4(c) and 4(e), we noticed that the structure was slightly dastard in case of $2 \%$ Aluminum oxide filled treated cotton stalk-novolac difference. In $4 \%$ aluminum oxide $\left(\mathrm{Al}_{2} \mathrm{O}_{3}\right)$ filled treated cotton stalk-novolac composite (4(d)) the total structure is found to have disturbed no platelet-like structure has been observed. This indicates that the addition of $\mathrm{Al}_{2} \mathrm{O}_{3}$ powder has destroyed a well organized crystalline pattern of novolac composite following lamella and has a disturbed crystalline arrangement. Also in $6 \% \mathrm{Al}_{2} \mathrm{O}_{3}$-filled novolac composite (4(e)), the morphological structure is just similar to pure novolac composite. The crystallinity as well as crystallite. Size of pure and $6 \% \mathrm{Al}_{2} \mathrm{O}_{3}$-filled novolac sample are also nearly the same. This indicates $6 \% \mathrm{Al}_{2} \mathrm{O}_{3}$ added in treated cotton stalk novolac composite occupied space in the voids formed during sample preparation [24].

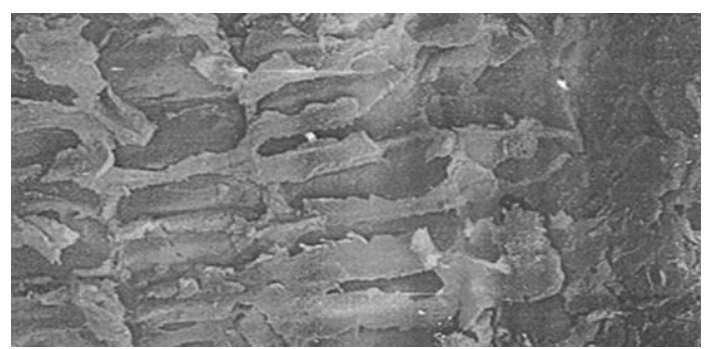

(a)

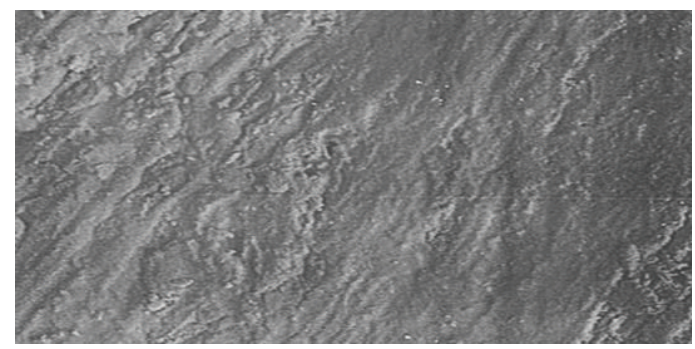

(b)

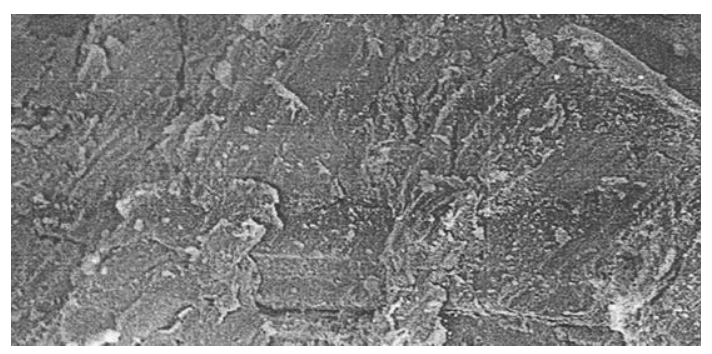

(c)

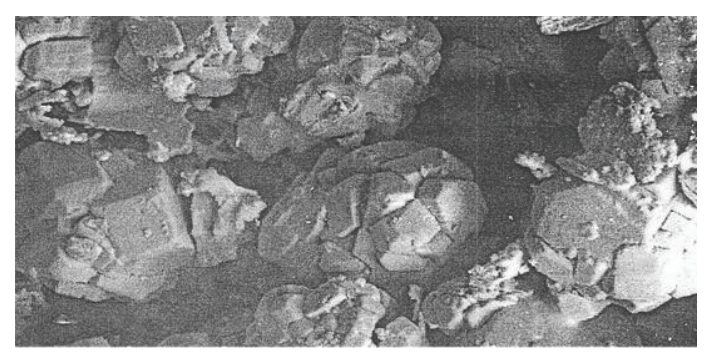

(d)

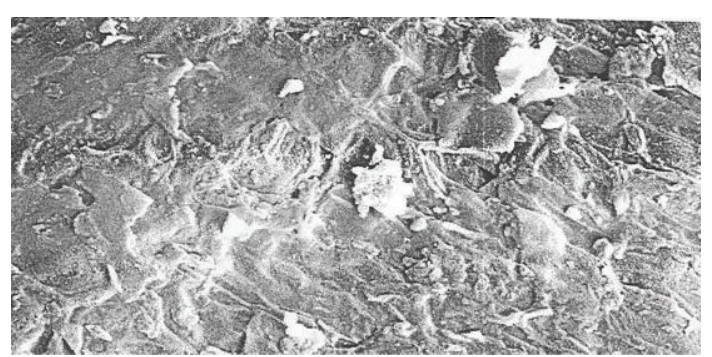

(e)

FIGURE 4: SEM of cotton stalk. (a) Untreated composite containing $30 \%$ novolac resin. (b) Treated composite containing 30\% novolac resin. (c) Treated composite containing 30\% novolac resin and 2\% aluminum oxide. (d) Treated composite containing 30\% novolac resin and $4 \%$ aluminum oxide. (e) Treated composite containing $30 \%$ novolac resin and $6 \%$ aluminum oxide. 


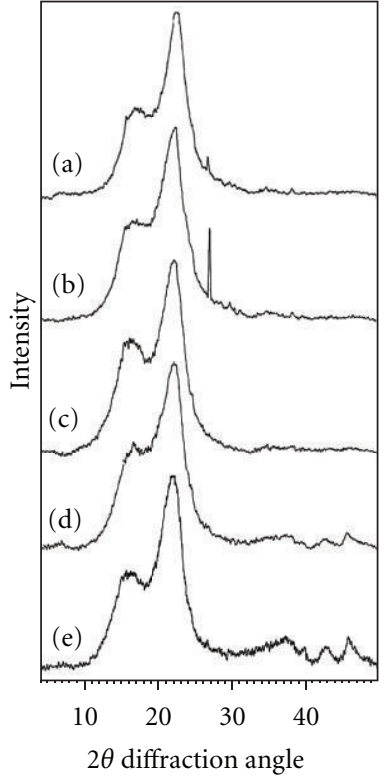

FIGURE 5: X-ray diffraction of cotton stalk. (a) Untreated composite containing 30\% novolac resin. (b) Treated composite containing $30 \%$ novolac resin. (c) Treated composite containing 30\% novolac resin and $2 \%$ aluminum oxide. (d) Treated composite containing $30 \%$ novolac resin and $4 \%$ aluminum oxide. (e) Treated composite containing $30 \%$ novolac resin and $6 \%$ aluminum oxide.

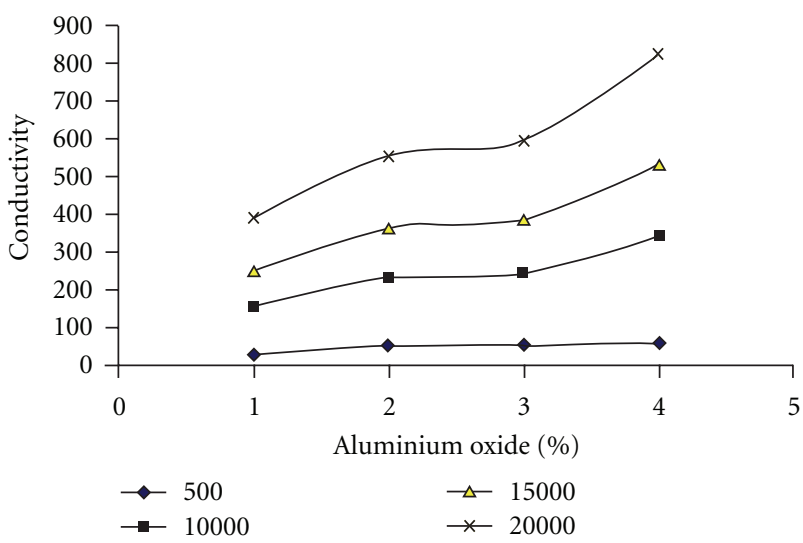

FIgURE 6: Effect of aluminum oxide \% on the conductivity.

3.4. X-Ray Diffraction. It is clear from X-ray diffractogram shown in Figure 5. It is possible to observe a major diffraction peak for 20 between $22^{\circ}$ and $23^{\circ}$ which corresponds to the cellulose fibers (002) crystallographic plane [25].

In similar form to those reported for others lignocellulosic fibers. According to Rodrigues [26], this method to determine the lignocellulose fiber crystallinity index provides simple and fast information. The crystallinity index (CI) was calculated as the ratio of the intensity differences in the peak positions at $16^{\circ}$ and $22^{\circ}$ according to equation:

$$
\mathrm{CI}=\left[\frac{\left(I_{22}-I_{16}\right)}{I_{22}}\right] \times 100,
$$

TABLE 2: Crystallinity degree for novolac-modified composite with different concentration of aluminum oxide added.

\begin{tabular}{lccccc}
\hline Sample & A & B & C & D & E \\
\hline CI & $45.9 \%$ & $49.20 \%$ & $52.40 \%$ & $65.22 \%$ & $74.18 \%$ \\
\hline
\end{tabular}

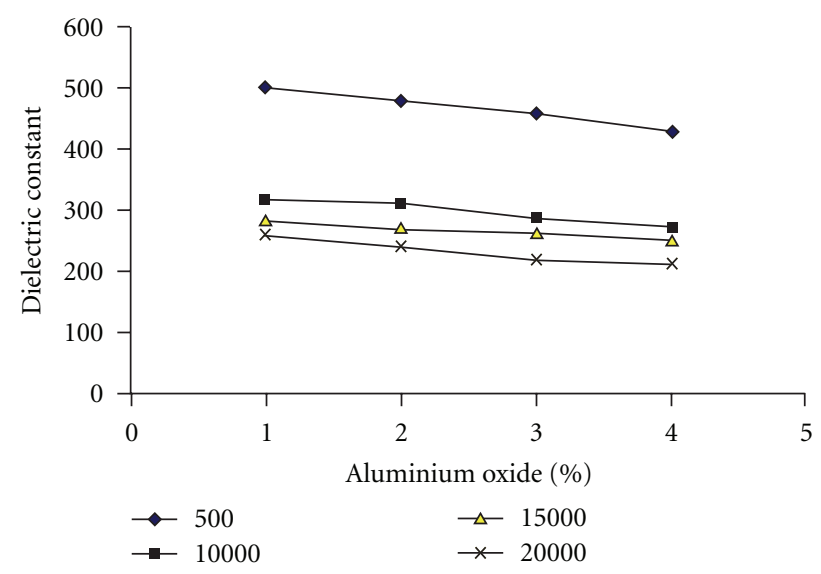

FIgURE 7: Effect of aluminum oxide \% on the dielectric constant.

where $I_{16}$ the intensity at minimum $\left(16^{\circ}<2 \theta<19^{\circ}\right)$ and $I_{22}$ is the intensity at maximum $\left(22^{\circ}<2 \theta<23^{\circ}\right)$. According to this method the degree of the crystallinity values were calculated (Table 2).

3.5. Electrical Properties. Table 3 and Figures 6 and 7 show the comparison between the dielectric constant and the conductivity of the treated samples with or without different percent of aluminum oxide. It is clear that the conductivity of the treated composite without aluminum oxide had lower value than the treated composite containing aluminum oxide. The more percent of aluminum oxide, the more value of conductivity was obtained at different frequencies. At frequency $500 \mathrm{~Hz}$, the conductivity of the treated composite without aluminum oxide was 30.8 and increased to 54.2, 56.2 , and 61.5 after addition of 2,4 , and $6 \%$ aluminum oxide, respectively. Also at frequency $20.000 \mathrm{~Hz}$, the conductivity of the treated composite without aluminum oxide was 395.5 but after addition of aluminum oxide 2, 4 and $6 \%$, the conductivity became $556.7,595.4$, and 822.9 , respectively. This is due to the fact that aluminum oxide had a good electrical property and used to impart more sophisticated properties to the materials such as magnetic or electrical properties [17]. Also Table 3 shows that the dielectric constant decreased when added aluminum oxide and more percent aluminum oxide leads to lower value of dielectric constant at different frequencies. At frequency $500 \mathrm{~Hz}$, the dielectric constant of the treated composite without aluminum oxide was 500.2 and decreased to $478.8,458.1$, and 426.2 after addition of 2 , 4 , and $6 \%$, respectively. At frequency $20.000 \mathrm{~Hz}$, the dielectric constant of the treated composite was 260 but after addition of aluminum oxide 2,4 , and $6 \%$ the dielectric constant were $240.4,220.4$, and 212.8 , respectively. 
TABLE 3: Effect of aluminum oxide percent on the conductivity and dielectric constant of treated composite.

\begin{tabular}{|c|c|c|c|}
\hline Sample & Frequency $\mathrm{Hz}$ & Conductivity $\left(\sigma_{A}\right) \mathrm{S} / \mathrm{cm}$ & Dielectric constant $\left(\varepsilon^{\prime}\right)$ \\
\hline $\begin{array}{l}\text { (1) Treated composite by propionic anhydride containing } \\
30 \% \text { novolac }\end{array}$ & 500 & $30.9 E-8$ & 500.2 \\
\hline $\begin{array}{l}\text { (2) Treated composite by propionic anhydride containing } \\
30 \% \text { novolac and } 2 \% \text { aluminum oxide }\end{array}$ & 500 & $54.2 E-8$ & 478.8 \\
\hline $\begin{array}{l}\text { (3) Treated composite by propionic anhydride containing } \\
30 \% \text { novolac and } 4 \% \text { aluminum oxide }\end{array}$ & 500 & $56.2 E-8$ & 458.1 \\
\hline $\begin{array}{l}\text { (4) Treated composite by propionic anhydride containing } \\
30 \% \text { novolac and } 6 \% \text { aluminum oxide }\end{array}$ & 500 & $61.5 E-8$ & 426.2 \\
\hline 1 & \multirow{4}{*}{10.000} & $157.3 E-8$ & 316.4 \\
\hline 2 & & $234.8 E-8$ & 310.7 \\
\hline 3 & & $246.9 E-8$ & 285.3 \\
\hline 4 & & $341.5 E-8$ & 271.5 \\
\hline 1 & \multirow{4}{*}{15.000} & $252.2 E-8$ & 280.3 \\
\hline 2 & & $362.6 E-8$ & 268.1 \\
\hline 3 & & $384.8 E-8$ & 262.2 \\
\hline 4 & & $532.5 E-8$ & 250.3 \\
\hline 1 & \multirow{4}{*}{20.000} & $395.5 E-8$ & 260 \\
\hline 2 & & $556.7 E-8$ & 240.4 \\
\hline 3 & & $595.4 E-8$ & 220.4 \\
\hline 4 & & $822.9 E-8$ & 212.8 \\
\hline
\end{tabular}

\section{Conclusion}

(1) Mechanical and water repellency of cotton stalk fibers esterified with propionic anhydride that are used as reinforcing in novolac resin are greatly improved than untreated.

(2) Adding aluminum oxide improved bending strength, enhanced water repellent and altered the conductivity and dielectric constant of the composite.

(3) The conductivity of the treated composite without aluminum oxide had lower value than the treated composite containing aluminum oxide. The more percent of aluminum oxide, the more value of conductivity at different frequencies obtained.

(4) The crystallinity index increased with increasing the percent of aluminum oxide.

\section{References}

[1] A. K. Bledzki, S. Reihmane, and J. Gassan, "Properties and modification methods for vegetable fibers for natural fiber composites," Journal of Applied Polymer Science, vol. 59, no. 8, pp. 1329-1336, 1996.

[2] A. K. Bledzki, S. Reihmane, and J. Gassan, "Thermoplastics reinforced with wood fillers: a literature review," Polymer, vol. 37, no. 4, pp. 451-468, 1998.

[3] A. K. Bledzki and J. Gassan, "Composites reinforced with cellulose based fibres," Progress in Polymer Science, vol. 24, no. 2, pp. 221-274, 1999.
[4] D. De, D. Debapriya, and B. Adhikari, "The effect of grass fiber filler on curing characteristics and mechanical properties of natural rubber," Polymers for Advanced Technologies, vol. 15, no. 12, pp. 708-715, 2004.

[5] M. Jacob, B. Francis, S. Thomas, and K. T. Varughese, "Dynamical mechanical analysis of sisal/oil palm hybrid fiber-reinforced natural rubber composites," Polymer Composites, vol. 27, no. 6, pp. 671-680, 2006.

[6] A. S. Singha, A. Shama, and B. N. Misra, "Pressure induced graft copolymerization of binary vinyl monomer mixtures onto Saccharum cilliare fiber and evaluation of some physical, chemical and thermal properties," Journal of Polymer Materials, vol. 25, no. 1, pp. 93-101, 2008.

[7] A. S. Singha, A. Shama, and V. K. Thakur, "Pressure induced graft-co-polymerization of acrylonitrile onto Saccharum cilliare fibre and evaluation of some properties of grafted fibre," Bulletin of Materials Science, vol. 31, no. 1, pp. 7-13, 2008.

[8] G. S. Chauhan, I. Kaur, B. N. Misra, A. S. Singha, and B. S. Kaith, "Modification of Natural Polymers: Graft co-polymerization of Methyl methacrylate onto Rayon Fibre Initiated by Ceric Ions - A Study in the Swelling and Thermal Properties," Journal of Polymer Materials, vol. 16, pp. 245-252, 1999.

[9] G. S. Chauhan, S. S. Bhatt, I. Kaur, A. S. Singha, and B. S. Kaith, "Evaluation of optimum grafting parameters and the effect of ceric ion initiated grafting of methyl methacrylate on to jute fibre on the kinetics of thermal degradation and swelling behaviour," Polymer Degradation and Stability, vol. 69, no. 3, pp. 261-265, 2000.

[10] B. S. Kaith, A. S. Singha, and S. Kalia, "Grafting MMA onto flax under the influence of microwave radiation and the use of flax-g-poly(MMA) in preparing PF composites," Autex Research Journal, vol. 7, no. 2, pp. 119-129, 2007. 
[11] B. S. Kaith, A. S. Singha, S. Kumar, and S. Kalia, "Mercerization of flax fiber improves the mechanical properties of fiberreinforced composites," International Journal of Polymeric Materials, vol. 57, no. 1, pp. 54-72, 2008.

[12] S. Panthapulakkal, A. Zereshkian, and M. Sain, "Preparation and characterization of wheat straw fibers for reinforcing application in injection molded thermoplastic composites," Bioresource Technology, vol. 97, no. 2, pp. 265-272, 2006.

[13] S. D. Nabi and J. Jog, "Natural fiber polymer composites: a review," Advances in Polymer Technology, vol. 18, no. 4, pp. 351-363, 1999.

[14] A. N. Nakagiato and H. Yano, "The effect of morphological changes from pulp fibre towards nano-scale fibrillated cellulose on the mechanical properties of high-strength plant fibre based composites," Applied Physics A, vol. 78, pp. 547-525, 2004.

[15] P. O. Hagstrand and K. Oksman, "Mechanical properties and morphology of flax fiber reinforced melamine-formaldehyde composites," Polymer Composites, vol. 22, no. 4, pp. 568-578, 2001.

[16] G. A. Aierbea, J. M. Echeverra, M. D. Martina, A. M. Etxeberria, and I. Mondragona, "Influence of the initial formaldehyde to phenol molar ratio ( $\mathrm{F} / \mathrm{P})$ on the formation of a phenolic resol resin catalyzed with amine," Polymer, vol. 41, no. 18, pp. 6797-6802, 2004.

[17] Z. Liu, T. Fan, W. Zhang, and D. Zhang, "The synthesis of hierarchical porous iron oxide with wood templates," Microporous and Mesoporous Materials, vol. 85, no. 1-2, pp. 82-88, 2005.

[18] C. M. Thompson, H. M. Herring, T. S. Gates, and J. W. Connell, "Preparation and characterization of metal oxide/ polyimide nanocomposites," Composites Science and Technology, vol. 63, no. 11, pp. 1591-1598, 2003.

[19] S. H. Mansour, M. A. Eid, and Z. A. Nagieb, "Effect of acid anhydrides as modifiers on the physical and electrical properties of sawdust and rice straw pulp," Energy, Education Science and Technology, vol. 20, pp. 87-100, 2008.

[20] ASTM, Standard Test Method for Water Absorption of Plastics, ASTM, Philadelphia, Pa, USA, 1990.

[21] M. G. El-Meligy, S. H. Mohamed, and R. M. Mahani, "Study mechanical, swelling and dielectric properties of prehydrolysed banana fiber-waste polyurethane foam composites," Carbohydrate Polymers, vol. 80, no. 2, pp. 367-373, 2010.

[22] S. Kamel, A. M. Adel, M. El-Sakhawy, and Z. A. Nagieb, "Mechanical properties and water absorption of low-density polyethylene/sawdust composites," Journal of Applied Polymer Science, vol. 107, no. 2, pp. 1337-1342, 2008.

[23] M. Kazayawoko, J. J. Balatineez, and R.T. Woodhans, “Diffuse reflectance Fourier transform infrared spectra of wood fibers treated with maleated polypropylenes," Journal of Applied Polymer Science, vol. 66, no. 6, pp. 1163-1173, 1997.

[24] Q. Li and L. M. Matuana, "Surface of cellulosic materials modified with functionalized polyethylene coupling agents," Journal of Applied Polymer Science, vol. 88, no. 2, pp. 278-286, 2003.

[25] D. B. Mawhinney, V. Naumenko, A. Kuznetsova, J. T. Yates, J. Liu, and R. E. Smalley, "Infrared spectral evidence for the etching of carbon nanotubes: ozone oxidation at $298 \mathrm{~K}$," Journal of the American Chemical Society, vol. 122, no. 10, pp. 2383-2384, 2000.

[26] E. Minopoulou, E. Dessipri, G. D. Chryssikos, V. Gionis, A. Paipetis, and C. Panayiotou, "Use of NIR for structural characterization of urea-formaldehyde resins," International Journal of Adhesion and Adhesives, vol. 23, no. 6, pp. 473-484, 2003. 

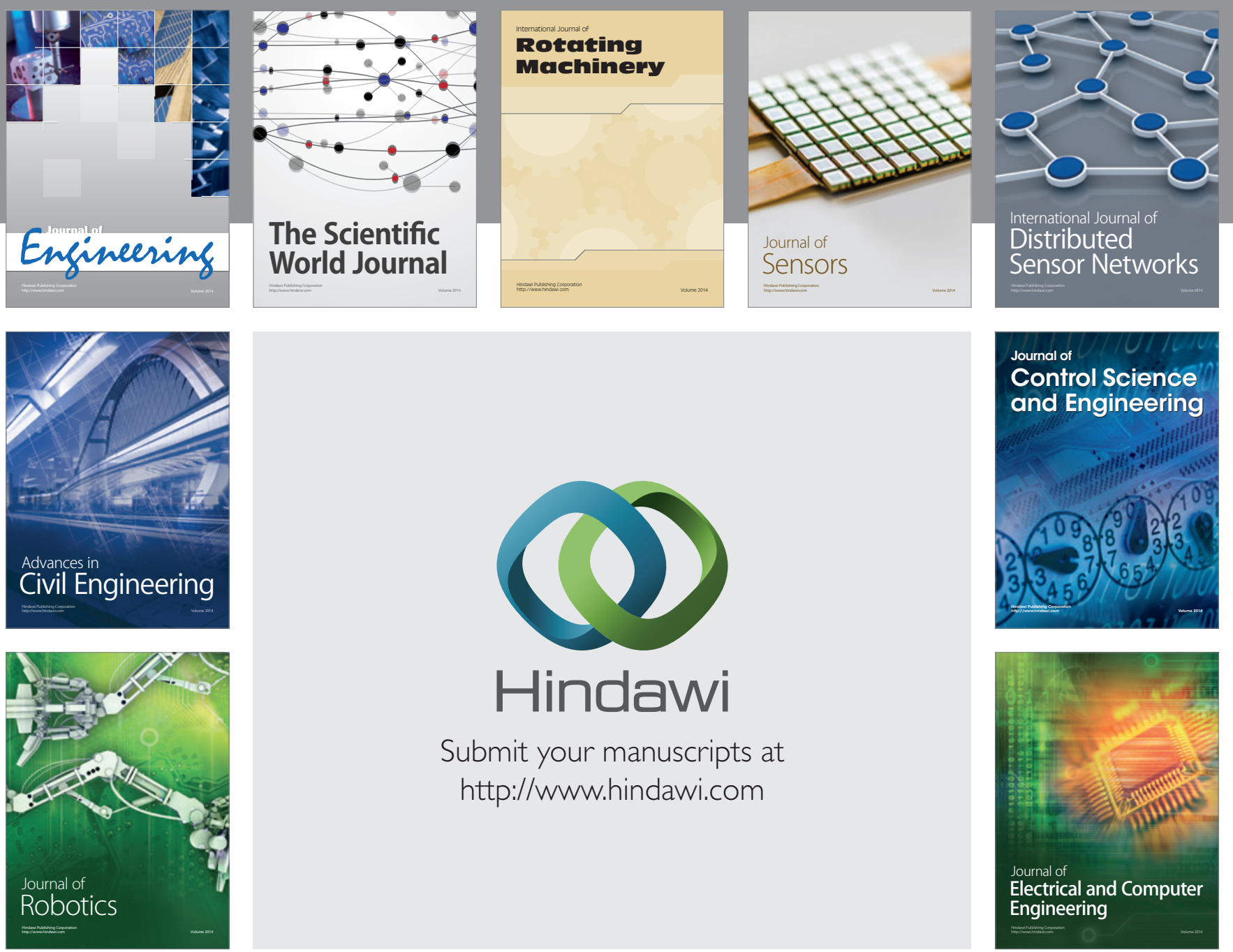

Submit your manuscripts at

http://www.hindawi.com
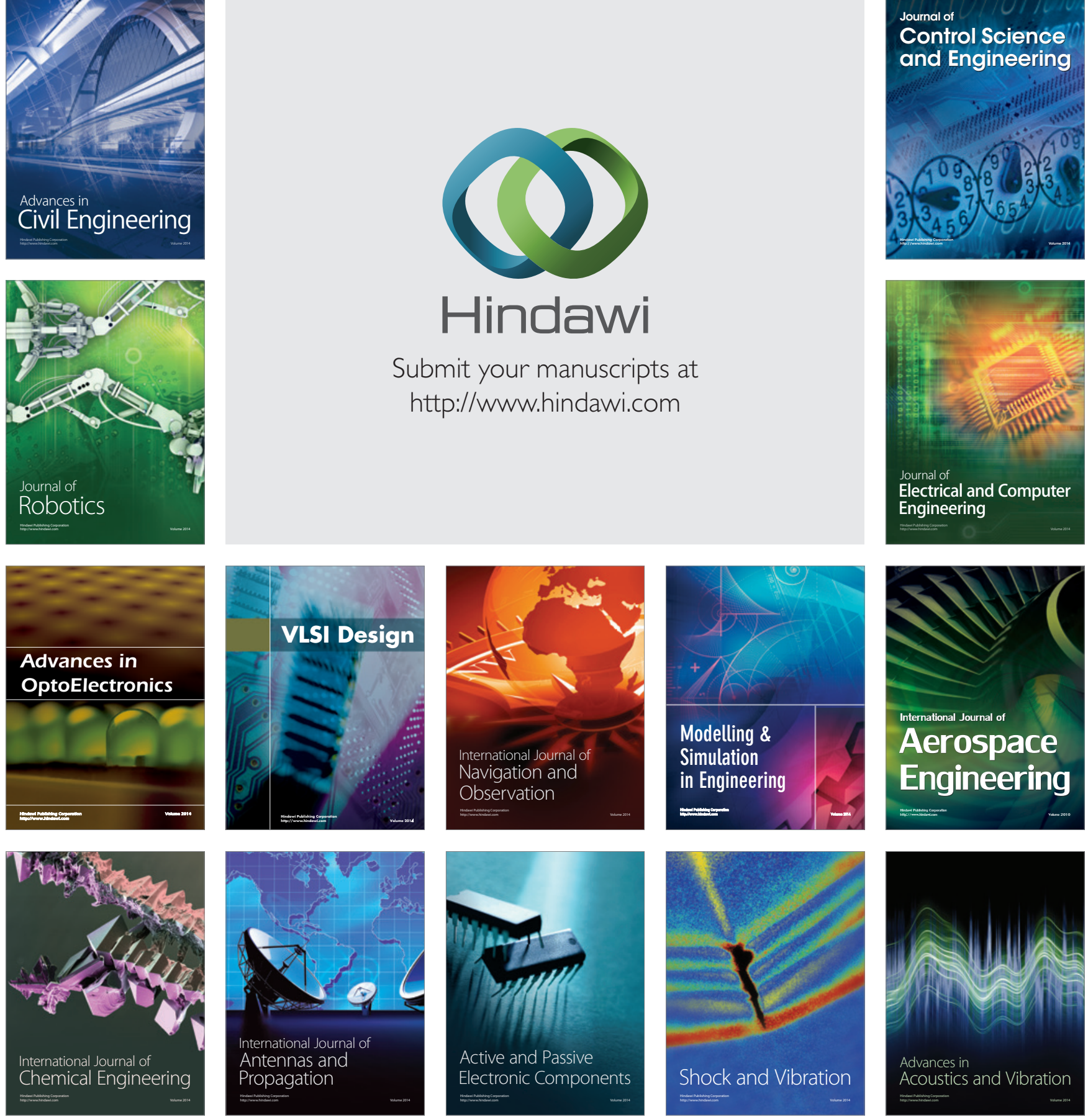